\title{
Apolipoprotein C in Type 2 (Non-Insulin-Dependent) Diabetic Patients with Hypertriglyceridaemia
}

\author{
A. F. H. Stalenhoef, P. N. M. Demacker, J. A. Lutterman and A.van't Laar \\ Department of Medicine, University of Nijmegen, St. Radboud Hospital, Nijmegen, The Netherlands
}

Summary. The composition of apolipoprotein $\mathrm{C}$ of the very low density lipoproteins (VLDL) was examined in 23 treated Type 2 (non-insulin-dependent) diabetic patients, who had elevated VLDL concentrations. Apolipoprotein $\mathrm{C}$ was separated by isoelectric focussing into apolipoprotein C-II which is known as the specific activator of lipoprotein lipase, and three apolipoprotein C-III fragments. A regulatory role has been ascribed to the ratio of apolipoprotein C-II to apolipoprotein C-III in the removal of plasma triglycerides. In our diabetic group, the composition of apolipoprotein $\mathrm{C}$ of the VLDL particles was not different from that of a healthy control group. In particular, the above apolipoprotein ratio and the relative amounts of apolipoprotein C-III fragments were normal. Hypertriglyceridaemia in these diabetic subjects does not seem to be related to alterations in the apolipoprotein C composition.

Key words: Type 2 diabetes, triglycerides, VLDL, apolipoprotein C.

Apolipoprotein $\mathrm{C}$ (apoC) is a major protein of human plasma chylomicrons and very low density lipoproteins (VLDL). ApoC consists of several polypeptides, of which apolipoprotein C-II (apoC-II) is the specific activator of lipoprotein lipase. Apolipoprotein C-III (apoC-III) is a glycoprotein containing 0,1 or $2 \mathrm{~mol}$ of sialic acid; these peptides are designated apoC-III 0 apoC-III ${ }_{1}$ and apoC- $\mathrm{III}_{2}$, respectively. Since apoCIII opposes the effect of apoC-II on lipoprotein lipase in vitro, a regulatory role has been ascribed to the ratio of apoC-II to apoC-III in the removal of plasma triglycerides $[1,2]$. The role of apoC-III in vivo, however, remains uncertain.
Recently, Gabor et al. [3] reported an increase in the relative amount of apoC- $-\mathrm{III}_{1}$ and a consequent decrease in the ratio apoC-II/apoC-III ${ }_{1}$ of the VLDL fraction in six patients with Type 2 (non-insulin-dependent) diabetes and elevated VLDL levels. These authors used polyacrylamide gel electrophoresis in urea $(8 \mathrm{~mol} / 1)$ to quantitate the apoproteins. By this method no resolution is obtained of apoC- $\mathrm{III}_{0}$. In search of further evidence for a possible pathogenetic role for an abnormal VLDL apoC composition, we examined serum samples of 23 patients with Type 2 diabetes and Type IV hyperlipoproteinaemia, using analytical isoelectric focussing for the separation of the apoproteins.

\section{Patients and Methods}

For the purpose of the study, 23 patients with diabetes and hypertriglyceridaemia (12 males, 11 females) were examined. Their mean age was $57.5 \pm 5.9$ years ( \pm SD) and the mean relative body weight was $123 \pm 14 \%$ (calculated from mean ideal body weight for height). The mean duration of diabetes was 7.0 years (range $0.5-23$ years). They were treated with either diet alone (nine subjects) or by diet in combination with sulphonylurea (12 subjects) and insulin (two subjects). Normolipidaemic subjects (14 males, eight females) chosen from healthy hospital personnel served as the control group, although their mean age of $37.0 \pm 7.3$ years and mean relative body weight of $105 \pm 6 \%$ were significantly different from those of the patients. Plasma was obtained after an overnight fast. The lipoproteins were isolated by preparative ultracentrifugation as described previously [4]. Cholesterol was determined with an enzymatic method and triglycerides with a semi-automated colorimetric method [4]. The apoprotein C composition of the VLDL-fraction was determined with isoelectric focussing $[5,6]$. VLDL was washed by a subsequent ultracentrifugation and delipidated in acetone: ethanol $(1: 1 \mathrm{v} / \mathrm{v})$. After isoelectric focussing the apoproteins were stained with Coomassie blue, followed by densitometric scanning. There was a linear relationship between the amount of VLDL apoproteins loaded on the gel and the densitometric response [6]. No correction was made for higher apoC-II chromogenicity [7, 8].

Results are expressed as mean \pm SD. For statistical analysis Student's t-test and the Wilcoxon test for unpaired data were used. 
Table 1. Plasma triglyceride concentrations, distribution of apolipoprotein C-III subspecies and apolipoprotein C-II/C-III ratio in very low density lipoproteins from hypertriglyceridaemic diabetic and normal subjects

\begin{tabular}{|c|c|c|c|c|c|c|}
\hline & \multicolumn{2}{|c|}{ Triglycerides $(\mathrm{mmol} / \mathrm{l})$} & $\mathrm{C}-\mathrm{III}_{0}$ & $\mathrm{C}-\mathrm{III}_{1}$ & $\mathrm{C}-\mathrm{III}_{2}$ & \multirow{2}{*}{$\begin{array}{l}\text { apoC-II/apoC-III } \\
\text { ratio }\end{array}$} \\
\hline & Total & VLDL & \multicolumn{3}{|c|}{$\%$ of total VLDL apoC-III } & \\
\hline Diabetic patients $(n=23)$ & $3.60 \pm 1.12^{a}$ & $2.80 \pm 1.02^{\mathrm{a}}$ & $18.9 \pm 4.6$ & $44.8 \pm 5.5$ & $36.1 \pm 5.2$ & $0.19 \pm 0.07$ \\
\hline Control subjects $(n=22)$ & $1.04 \pm 0.38$ & $0.55 \pm 0.29$ & $17.2 \pm 5.3$ & $44.4 \pm 3.6$ & $38.7 \pm 3.8$ & $0.18 \pm 0.07$ \\
\hline
\end{tabular}

Results are presented as mean $\pm \mathrm{SD}$

${ }^{a} p<0.001$ versus control subjects

\section{Results}

The mean fasting plasma glucose level in the diabetic subjects at the time of blood sampling for lipoproteins was $11.5 \pm 4.3 \mathrm{mmol} / 1$. By selection plasma triglyceride concentrations were elevated in the diabetic subjects (Table 1). Chylomicrons were not present and plasma low density lipoprotein-cholesterol concentration was normal $(<5.2 \mathrm{mmol} / \mathrm{l})$, so that all subjects had Type IV hyperlipoproteinaemia.

The results of the measurement of the relative amounts of the VLDL apoC-III peptides and the ratio apoC-II/apoC-III are presented in Table 1. Our results for the determination of the VLDL apoC-II/ apoC-III ratio in the normolipidaemic group are comparable with those reported by Catapano [7]. The distribution of the variously sialylated forms of apoCIII in the diabetic groups was not significantly different from that in the control group. The relative amount of VLDL apoC- $\mathrm{III}_{1}$ was not increased. The ratio apoC-II/apoC-III was not decreased.

\section{Discussion}

In primary Type IV hyperlipoproteinaemia normal apoC-II/apoC-III ratios have been reported by Schonfeld et al. [9], both in total plasma and the VLDL fraction (assessed by radioimmunoassay) and by Kashyap et al. [8] (when measured by isoelectric focussing). The latter authors found a significantly higher content of apoC- $\mathrm{III}_{1}$ only in patients with Type V hyperlipoproteinaemia, and a lower content of apoC-III ${ }_{0}$ in the $d<1.006 \mathrm{~g} / \mathrm{ml}$ fraction. Catapano [7] reported decreased ratios of apoC-II/apoC-III in Type IV patients (by isoelectric focussing), as has been found by Carlson and Ballantyne [1] using polyacrylamide gel electrophoresis. These conflicting results may be caused by the different techniques used.

Only a few detailed studies have been reported concerning the VLDL apoprotein $\mathrm{C}$ composition in adult diabetic patients. Pagnan et al. [10] measured a decreased mean relative amount of apoC- $\mathrm{III}_{0}$ in normolipidaemic subjects with diabetes; no differences in apoprotein $C$ composition were found between patients treated with insulin or tolbutamide. Gabor et al. [3] found an increase in the relative amount of apoC-III ${ }_{1}$ in patients with diabetes and elevated VLDL levels. In contrast to these data we found, in a larger group of patients with Type 2 diabetes and Type IV hyperlipoproteinaemia, a normal apoC composition of the VLDL fraction. Neither apoC- $\mathrm{III}_{0}$ and apoC-III ${ }_{1}$ were increased in our diabetic group, so the differences from the data of Gabor et al. cannot be explained by the lack of resolution of apoC- $\mathrm{III}_{0}$ with the method used by these authors. The ratio of apoC-II/apoC-III was also not decreased. Increased hepatic VLDL production and/or impaired VLDL removal are known to be the basic defects in the mechanism of hypertriglyceridaemia. Alterations in apoprotein C composition of the VLDL particles do not, however, seem to play a pathogenetic role.

\section{References}

1. Carlson LA, Ballantyne D (1976) Changing relative proportions of apolipoproteins C-II and C-III of very low density lipoproteins in hypertriglyceridemia. Atherosclerosis 23: 563-568

2. Kashyap ML, Srivastava LS, Chen CY, Perisutti G, Campbell M, Lutmer RF, Glueck GJ (1977) Radioimmunoassay of human apolipoprotein C-II. A study in normal and hypertriglyceridemic subjects. J Clin Invest 60: 171-180

3. Gabor J, Spain M, Kalant N (1980) Composition of serum verylow-density and high-density lipoproteins in diabetes. Clin Chem 26: 1261-1265

4. Demacker PNM, Vos-Janssen HE, Jansen AP, van 't Laar A (1977) Evaluation of the dual-precipitation method by comparison with the ultracentrifugation method for measurement of lipoproteins in serum. Clin Chem 23:1238-1244

5. Weidman SW, Suarez B, Falko JM, Witztum JL, Kolar J, Raben M, Schonfeld G (1979) Type III hyperlipoproteinemia: development of a VLDL apo E gel isoelectric focusing technique and application in family studies. J Lab Clin Med 93: 549-569 
6. Stalenhoef AFH, Casparie AF, Demacker PNM, Stouten JTJ, Lutterman JA, van 't Laar A (1981) Combined deficiency of apolipoprotein C-II and lipoprotein lipase in familial hyperchylomicronemia. Metabolism 30:919-926

7. Catapano AL (1980) The distribution of apo C-II and apo C-III in very low density lipoproteins of normal and type IV subjects. Atherosclerosis $35: 419-424$

8. Kashyap ML, Hynd BA, Robinson K, Gartside PS (1981) Abnormal preponderance of sialylated apolipoprotein C-II in triglyceride-rich lipoproteins in type $\mathrm{V}$ hyperlipoproteinemia. Metabolism 30: 111-118

9. Schonfeld G, George PK, Miller J, Reilly P, Witztum J (1979) Apolipoprotein C-II and C-III levels in hyperlipoproteinemia. Metabolism 28: 1001-1010
10. Pagnan A, Padovan D, Guarini P, Teodoro N, Zanetti G (1980) Serum lipids and apoprotein composition (\%) of the very low density lipoprotein (VLDL) fraction in two groups of diabetic patients: effects of oral as compared to insulin therapy. Acta Diabetol Lat 17:225-228

Received: 19 October 1981

and in revised form: 28 January 1982

A. Stalenhoef, MD

Department of Medicine

St. Radboud Hospital

P.O. Box 9101

$6500 \mathrm{HB}$ Nijmegen, The Netherlands 